\title{
Restrictive mitral valve annuloplasty versus mitral valve replacement for functional ischemic mitral regurgitation: An exercise echocardiographic study
}

Carlo Fino, MD, ${ }^{\mathrm{a}, \mathrm{c}}$ Attilio Iacovoni, MD,${ }^{\mathrm{a}}$ Paolo Ferrero, MD, ${ }^{\mathrm{a}}$ Michele Senni, MD, ${ }^{\mathrm{a}}$ Maurizio Merlo, MD, ${ }^{\mathrm{a}}$ Diego Cugola, $\mathrm{MD},{ }^{\mathrm{a}}$ Paolo Ferrazzi, MD, ${ }^{\mathrm{a}}$ Massimo Caputo, $\mathrm{MD},{ }^{\mathrm{c}}$ Antonio Miceli, $\mathrm{MD}, \mathrm{PhD},{ }^{\mathrm{c}}$ and Julien Magne, $\mathrm{PhD}^{\mathrm{b}}$

Objective: Mitral valve annuloplasty and mitral valve replacement are common strategies for the management of functional ischemic mitral regurgitation with ischemic cardiomyopathy. However, mitral valve annuloplasty may create some degree of functional mitral stenosis. The purpose of this study was to compare the mitral valve hemodynamics in patients with functional ischemic mitral regurgitation undergoing mitral valve annuloplasty or mitral valve replacement, using exercise echocardiography.

Methods: We performed resting and exercise echocardiography in 70 patients matched for indexed effective orifice area, systolic pulmonary arterial pressure, and left ventricular ejection fraction after mitral valve annuloplasty or mitral valve replacement with coronary artery bypass grafting.

Results: There was no significant difference between the 2 groups regarding baseline demographic and clinical data. Exercise systolic pulmonary arterial pressure was higher in the mitral valve annuloplasty group compared with the mitral valve replacement group (from $36.3 \pm 8.1 \mathrm{~mm} \mathrm{Hg}$ to $55 \pm 12 \mathrm{~mm} \mathrm{Hg}$, vs mitral valve replacement: $33 \pm 6 \mathrm{~mm} \mathrm{Hg}$ to $42 \pm 6.2 \mathrm{~mm} \mathrm{Hg}, P=.0001)$. Exercise-induced improvement in effective orifice area and indexed effective orifice area was better in the mitral valve replacement group (mitral valve replacement: $+0.23 \pm 0.04$ vs mitral valve annuloplasty: $-0.1 \pm 0.09$ $\mathrm{cm}^{2}, P=.001$, for effective orifice area; mitral valve replacement: $+0.14 \pm 0.03$ vs mitral valve annuloplasty: $-0.04 \pm 0.07 \mathrm{~cm}^{2} / \mathrm{m}^{2}, P=.03$, for indexed effective orifice area). Exercise indexed effective orifice area was correlated with exercise systolic pulmonary arterial pressure $(r=-0.45 ; P=.01)$. In a multivariable analysis mitral valve annuloplasty, postoperative indexed effective orifice area and resting mitral peak gradients were independent predictors of elevated systolic pulmonary arterial pressure during exercise.

Conclusions: In patients with functional ischemic mitral regurgitation, mitral valve annuloplasty may cause functional mitral stenosis, especially during exercise. Mitral valve annuloplasty was associated with poor exercise mitral hemodynamic performance, lack of mitral valve opening reserve, and markedly elevated postoperative exercise systolic pulmonary arterial pressure compared with mitral valve replacement. (J Thorac Cardiovasc Surg 2014;148:447-53)

\footnotetext{
From the Cardiovascular Department, ${ }^{\text {a }}$ Ospedale Papa Giovanni XXIII, Bergamo, Italy; Department of Cardiology, ${ }^{\mathrm{b}}$ University of Liège, GIGA Cardiovascular Sciences, Heart Valve Clinic, CHU Sart-Tilman, Liège, Belgium; and Bristol Heart Institute, ${ }^{\mathrm{c}}$ University of Bristol, Bristol, United Kingdom.

Funding: Dr Magne is a research associate from the F.R.S.-FNRS, Brussels, Belgium, and received grants from the Fonds Léon Fredericq, Liège, Belgium, and the Fond pour la Chirurgie Cardiaque, Belgium. The British Heart Foundation, National Institute for Health Research Bristol Biomedical Research Unit in Cardiovascular Medicine, and Garfield Weston Trust supported this work.

Disclosures: Authors have nothing to disclose with regard to commercial support.

Received for publication March 19, 2013; revisions received May 16, 2013; accepted for publication May 31, 2013; available ahead of print Nov 6, 2013.

Address for reprints: Julien Magne, $\mathrm{PhD}$, Université de Liège, CHU Sart Tilman, Domaine du Sart Tilman, B35, Service de Cardiologie, B-4000, Liège, Belgique (E-mail: jul.magne@yahoo.fr).

$0022-5223 / \$ 36.00$

Copyright (C) 2014 by The American Association for Thoracic Surgery

http://dx.doi.org/10.1016/j.jtcvs.2013.05.053
}

Functional ischemic mitral regurgitation (FIMR) is associated with poor outcome, and its best management remains controversial. $^{1-3}$ Mitral valve annuloplasty (MVA) and mitral valve replacement (MVR) combined with coronary artery bypass grafting represent the most common surgical strategies.

The rationale of restrictive MVA is to reduce the mitral annulus by shortening the anteroposterior distance with a prosthetic ring selected 2 sizes below the measured intertrigonal length. ${ }^{4}$ Recent studies suggest that MVA may create some degree of postoperative functional mitral 


$$
\begin{aligned}
& \text { Abbreviations and Acronyms } \\
& \text { AUC }=\text { area under the curve } \\
& \text { EOA }=\text { effective orifice area } \\
& \text { FIMR }=\text { functional ischemic mitral regurgitation } \\
& \text { IEOA }=\text { indexed effective orifice area } \\
& \text { LV }=\text { left ventricular } \\
& \text { LVEF }=\text { left ventricular ejection fraction } \\
& \text { LVOT }=\text { left ventricular outflow tract } \\
& \text { MR }=\text { mitral regurgitation } \\
& \text { MVA }=\text { mitral valve annuloplasty } \\
& \text { MVR }=\text { mitral valve replacement } \\
& \text { PH }=\text { pulmonary hypertension } \\
& \text { SD }=\text { standard deviation } \\
& \text { SPAP }=\text { systolic pulmonary arterial pressure } \\
& \text { SV }=\text { stroke volume }
\end{aligned}
$$

stenosis, thereby increasing systolic pulmonary arterial pressure (SPAP) and decreasing functional capacity, similarly to that observed in mitral stenosis or mitral prosthesis-patient mismatch. ${ }^{5-7}$

In the setting of FIMR, most studies comparing outcomes after MVA or MVR have evaluated mitral valve hemodynamics using resting Doppler echocardiography, ${ }^{8,9}$ which often does not correlate with patient symptoms. ${ }^{10}$ Exercise Doppler echocardiography represents a more reliable method to evaluate mitral valve hemodynamic performance. ${ }^{10}$

The aim of this study was to compare both resting and exercise mitral valve hemodynamic performance in patients undergoing surgical correction of FIMR. We designed this study to compare the hemodynamic performance of MVA with MVR and to identify the determinants of exercise SPAP.

\section{MATERIALS AND METHODS \\ Patient Population}

We retrospectively reviewed data prospectively collected on 194 consecutive patients with FIMR who underwent MVA or MVR combined with coronary artery bypass grafting, at the Cardiovascular Department, Ospedale "Papa Giovanni XXIII," Bergamo Italy, between February 2005 and August 2009. Ethical approval was given by the local hospital committee, and informed consent was obtained from all patients.

Indication for surgery was given during multidisciplinary meeting. Because there is no clear consensus on the superiority of MVA or MVR for severe FIMR, the choice between the 2 techniques was left to the surgeon performing each operation. Two high-volume senior surgeons (PF, MM) with special interest in mitral valve surgery and similar operative outcomes were involved in all the surgical procedures. Both groups received the same preoperative, operative, and postoperative care.

FIMR was defined by echocardiographic and coronary angiographic findings using the following criteria: MR occurring more than 1 week after myocardial infarction, as previously defined, ${ }^{11} 1$ or more left ventricular (LV) segmental wall motion abnormalities, significant coronary artery disease in the territory supplying the wall motion abnormality, and structurally normal mitral valve leaflets and chordae tendinae. ${ }^{11}$
Exclusion criteria were as follows: acute ischemic mitral regurgitation (MR); previous cardiac surgery or cardiac resynchronization therapy procedure; other significant valve disease (aortic, pulmonary, and tricuspid valve); concomitant ventricular procedures; inadequate preoperative echocardiogram; patients unable to exercise or unwilling to cooperate; chronic lung disease; and patients with recurrent MR, defined as a postoperative MR jet vena contracta width greater than $3 \mathrm{~mm}$, at the follow-up.

After the exclusion criteria were applied, the total population included 118 patients (MVA: $\mathrm{n}=72$; MVR: $\mathrm{n}=46$ ). There were 4 (3.4\%) perioperative deaths (deaths within 30 days or before discharge from the index hospitalization) without a significant difference between the patients receiving MVR or MVA (MVR: $\mathrm{n}=1[2.2 \%]$ vs MVA: $\mathrm{n}=3[4.2 \%]$, $P=.94)$.

The eligible population of 114 patients was prospectively contacted from June 2010 to August 2010 to perform both baseline resting and exercise Doppler echocardiography. These patients were then matched on a 1:1 basis in the following order: (1) indexed effective orifice area (IEOA), (2) SPAP, and (3) LV ejection fraction (LVEF). We accepted a positive match when the differences between 2 patients were less than $0.1 \mathrm{~cm}^{2} / \mathrm{m}^{2}$ in IEOA, less than $5 \mathrm{~mm} \mathrm{Hg}$ in SPAP, and less than $5 \%$ in LVEF. The final matched population included 70 patients. All data regarding the whole unmatched population are provided in Tables E1 to E3.

\section{Data Collection and Outcome Measures}

Coronary angiographic findings, preoperative clinical data, intraoperative clinical data, postoperative clinical data, and Doppler echocardiographic findings were prospectively collected in our institutional database and retrospectively analyzed.

\section{Surgical Technique}

Both procedures were performed by median sternotomy. In the MVA group, the ring sizer was selected by measuring the intercommissural distance of the mitral valve and positioned to cover the surface of the stretched middle scallop of the anterior leaflet. A Carpentier-Edwards Physio ring (Edwards Lifesciences, Irvine, Calif) undersized by 2 sizes was then inserted. In the MVR group, biological or mechanical prostheses were inserted with systematic preservation of the subvalvular apparatus. All coronary vessels with significant stenosis on the preoperative angiogram were grafted. Intraoperative transesophageal echocardiography was routinely used.

\section{Echocardiographic Protocol}

Resting and exercise echocardiography studies were performed using commercially available instruments (Vivid 7 imaging device; GE Healthcare, Little Chalfont, Buckinghamshire, United Kingdom). The echocardiographic and Doppler data were obtained at rest and at peak exercise in digital format and stored on a workstation for offline analysis (EchoPAC, GE Vingmed Ultrasound AS, Horten, Norway). Measurements were indexed to body surface area, when necessary, and the Doppler tracings were averaged from 3 to 5 beats.

According to the recommendations of the American Society of Echocardiography, ${ }^{12}$ the following parameters were measured: LV enddiastolic and end-systolic diameters; LVEF was measured using the modified biplane Simpson method; MR severity was assessed with the vena contracta width. LV outflow tract (LVOT) area was determined as $\pi \mathrm{D}^{2} / 4$, where $\mathrm{D}$ is the diameter measured from a zoomed systolic freeze-frame in the parasternal long-axis view. LV stroke volume (SV) was determined by multiplying the LVOT area to the time integral of the outflow tract velocity (pulsed-wave Doppler). Because LVOT area has been shown to remain constant during exercise, the resting value was used to calculate both rest and exercise SV. Cardiac output was calculated by multiplying the SV and the heart rate. 


\section{Mitral Hemodynamics}

The peak and mean transmitral pressure gradients were calculated using the modified Bernoulli equation. Mitral valve effective orifice area (EOA) was determined by the continuity equation using the SV divided by the integral of the mitral transvalvular velocity during diastole. The net atrioventricular compliance was calculated from the valve EOA and mitral flow E-wave downslope, as previously described. ${ }^{13,14}$ SPAP was calculated by adding the systolic right ventricular pressure derived from the tricuspid regurgitation to the estimated right atrial pressure. ${ }^{15}$

\section{Exercise Study}

A bicycle exercise test was performed in the semisupine position on a dedicated tilting exercise table. The initial workload was set at 0 Watt, followed by continuous increments of 10 to $25 \mathrm{Watt} / \mathrm{min}$, depending on the patient's physical condition. Continuous electrocardiograms were recorded, and the blood pressure was measured at baseline, every 2 minutes, and after each stage of exercise. Patients were encouraged to exercise until exhaustion or the onset of symptoms. Doppler hemodynamic measurements were obtained at peak exercise (ie, within the minute before and the minute after the end of exercise).

\section{Statistical Analysis}

Quantitative variables are expressed as mean \pm standard deviation. Differences between preoperative and postoperative data were tested by paired-samples $t$ test after checking for normality of distribution. Categoric variables are expressed as proportions and compared by chi-square or Fisher exact test as appropriate. Resting and stress variables between patients who underwent MVA and MVR were compared by 2-way analysis of variance for repeated measures. Associations between quantitative variables were evaluated by Pearson correlation test.

Independent determinants of exercise SPAP were investigated by multiple linear regression analysis, entering variables displaying a cutoff $P$ value less than 1 at the univariate analysis. The type of surgery (MVA or MVR) was included in the model as the dummy variable.

Area under the curve (AUC), sensitivity, and specificity for the prediction of the occurrence of exercise pulmonary hypertension $(\mathrm{PH})$ were determined for various cutoff values of resting echocardiographic parameters with receiver operating characteristic curves.

Interobserver variability was evaluated as the standard difference of the differences in each measurement, calculated by 2 independent observers for 10 different patients, expressed as the percent of mean (coefficient of variation) and $5 \%$ of the mean. Intraobserver variability, derived from repeated calculations 1 month apart, was $6 \%$. All statistical analysis was performed with SPSS 15.0 (SPSS Inc, Chicago, Ill).

\section{RESULTS}

\section{Patients' Characteristics and Operative Data}

Preoperative demographic, clinical, and operative data of the matched population are presented in Table 1. There was no significant difference between the 2 groups in terms of gender distribution, age, New York Heart Association class, and cardiovascular risk profile.

MVA was performed using Carpentier-Edwards Physio Ring size $26 \mathrm{~mm}$ in 6 patients $(17 \%), 28 \mathrm{~mm}$ in 18 patients $(51 \%), 30 \mathrm{~mm}$ in 10 patients $(29 \%)$, and $32 \mathrm{~mm}$ in 1 patient (3\%). In the MVR group, 8 patients (23\%) received a Carpentier-Edwards bioprosthesis size 27, 9 patients received size $29(26 \%)$, and 1 patient received size 31 (3\%). A mechanical St Jude Medical, Inc (St Paul, Minn) valve size 27 was used in 3 patients $(8 \%)$, size 29 was
TABLE 1. Preoperative demographic and clinical data

\begin{tabular}{|c|c|c|c|c|}
\hline & $\frac{\text { All patients }}{(n=70)}$ & $\frac{\text { MVR }}{(n=35)}$ & $\begin{array}{c}\text { MVA } \\
(\mathrm{n}=\mathbf{3 5}) \\
\end{array}$ & $P$ \\
\hline \multicolumn{5}{|l|}{ Demographic data } \\
\hline Male, n (\%) & $43(61)$ & $16(45)$ & $24(68)$ & . \\
\hline Age, $y$ & $64 \pm 5.4$ & $65 \pm 3.8$ & $64 \pm 5.1$ & .3 \\
\hline $\operatorname{BSA}\left(\mathrm{m}^{2}\right)$ & $1.67 \pm 0.24$ & $1.64 \pm 0.2$ & $1.69 \pm 0.25$ &. \\
\hline \multicolumn{5}{|l|}{ Clinical data } \\
\hline Diabetes, n (\%) & $16(23)$ & $6(17)$ & $10(28)$ & .35 \\
\hline $\begin{array}{l}\text { Systemic hypertension, } \\
\mathrm{n}(\%)\end{array}$ & $48(68)$ & $23(65)$ & $25(71)$ & .8 \\
\hline Smoking history, n (\%) & $52(74)$ & $23(65)$ & $29(82)$ & .3 \\
\hline Dyslipidemia, n (\%) & $43(61)$ & $20(57)$ & $23(65)$ & \\
\hline NYHA class III/IV, n (\%) & $29(41)$ & $10(28)$ & $19(54)$ & \\
\hline \multicolumn{5}{|l|}{ Operative data } \\
\hline CPB time (min) & $120 \pm 44$ & $119 \pm 38$ & $121 \pm 51$ & \\
\hline ACC time (min) & $90 \pm 31$ & $86 \pm 22$ & $93 \pm 38$ & \\
\hline CABG (No. of grafts) & $2.8 \pm 0.8$ & $2.7 \pm 0.7$ & $2.8 \pm 0.9$ & .6 \\
\hline \multicolumn{5}{|l|}{ Prosthesis type } \\
\hline Mechanical, n (\%) & & $17(49)$ & & \\
\hline Bioprosthesis, $\mathrm{n}(\%)$ & & $18(51)$ & & \\
\hline
\end{tabular}

Values are mean \pm standard deviation (SD) when appropriate. $A C C$, Aortic crossclamp; $B S A$, body surface area; $C A B G$, coronary artery bypass grafting; $C P B$, cardiopulmonary bypass; $M V A$, mitral valve annuloplasty; $M V R$, mitral valve replacement; NYHA, New York Heart Association.

used in 9 patients (26\%), and size 25 was used in 1 patient (3\%); a Carbomedics (Sorin Group, Milan, Italy) size 27 was used in 3 patients $(8 \%)$ and size 29 was used in 1 patient $(3 \%)$. All patients underwent coronary artery bypass grafting with no significant difference in terms of number of grafted vessels or procedural time in the 2 groups (Table 1).

\section{Preoperative and Postoperative \\ Doppler-Echocardiographic Data}

The median follow-up (ie, time between surgery and exercise stress echocardiography) was 30 months (interquartile range, 21-46 months) and was statistically significantly different between the 2 groups (MVA: 37 months, interquartile range, 25-52 months; MVR: 24 months, interquartile range, 14-38 months; $P=.01$ ).

In the MVR group, preoperative MR was severe in 31 patients $(88 \%)$ and moderate in 4 patients $(11 \%)$; in the MVA group, the MR was severe in 30 patients $(86 \%)$ and moderate in 5 patients $(14 \%)$. At the time of exercise echocardiography, New York Heart Association III-IV was $14 \%$ in the MVR group and $31 \%$ in the MVA group, with no statistical difference $(P=.15)$. The preoperative severity of MR was similar in the MVA and MVR groups (vena contracta width: $0.7 \pm 0.01 \mathrm{~cm}$ vs $0.7 \pm 0.02 \mathrm{~cm}$, respectively, $P=.9$; Table 2 ).

LV dimension significantly decreased within groups after surgery, with no significant difference between the 2 groups. There were no concomitant significant changes in LVEF and heart rate. 
TABLE 2. Preoperative and postoperative Doppler-echocardiographic data

\begin{tabular}{|c|c|c|c|c|c|c|}
\hline \multirow[b]{2}{*}{ Variables } & \multicolumn{2}{|c|}{$\operatorname{MVR}(\mathbf{n}=35)$} & \multicolumn{2}{|c|}{$\operatorname{MVA}(\mathbf{n}=\mathbf{3 5})$} & \multicolumn{2}{|c|}{ ANOVA $P$ value } \\
\hline & Preoperative & Postoperative & Preoperative & Postoperative & Within & Between \\
\hline \multicolumn{7}{|l|}{ LV geometry } \\
\hline LVED diameter, mm & $61 \pm 6$ & $56 \pm 5$ & 62. \pm 6 & 56. \pm 6 & .001 & .3 \\
\hline LVES diameter, $\mathrm{mm}$ & $48 \pm 7$ & $42 \pm 7$ & $52 \pm 13$ & $45 \pm 6$ & .001 & .3 \\
\hline Indexed LVED diameter, $\mathrm{mm} / \mathrm{m}^{2}$ & $36 \pm 3$ & $33 \pm 6$ & $36 \pm 6$ & $32 \pm 2$ & .001 & .9 \\
\hline Indexed LVES diameter, $\mathrm{mm} / \mathrm{m}^{2}$ & $26 \pm 5$ & $25 \pm 6$ & $30 \pm 5$ & $26 \pm 3$ & .003 & .6 \\
\hline \multicolumn{7}{|l|}{ LV function } \\
\hline LVEF, \% & $41 \pm 9$ & $41 \pm 6$ & $36 \pm 8$ & $40 \pm 4$ & .05 & .1 \\
\hline Heart rate, beats/min & $70 \pm 15$ & $71 \pm 8$ & $69 \pm 6$ & $73 \pm 12$ & .1 & .4 \\
\hline Cardiac output, $\mathrm{L} / \mathrm{min}$ & $4.5 \pm 1$ & $5 \pm 1$ & $4 \pm 0.5$ & $5 \pm 1$ & .08 & .6 \\
\hline Cardiac index, $\mathrm{L} / \mathrm{min} / \mathrm{m}^{2}$ & $1.8 \pm 1.3$ & $3 \pm 0.8$ & $1.7 \pm 1.3$ & $2.8 \pm 0.6$ & .001 & .9 \\
\hline \multicolumn{7}{|l|}{ Mitral valve hemodynamics } \\
\hline Peak gradient, $\mathrm{mm} \mathrm{Hg}$ & $4 \pm 0.7$ & $10 \pm 4$ & $3.6 \pm 0.8$ & $9 \pm 3.4$ & .001 & .9 \\
\hline Mean gradient, $\mathrm{mm} \mathrm{Hg}$ & $1.6 \pm 0.2$ & $5 \pm 2$ & $1.5 \pm 0.2$ & $4 \pm 1.3$ & .001 & .8 \\
\hline SPAP, mm Hg & $38 \pm 13$ & $33 \pm 6$ & $40 \pm 6$ & $37 \pm 9$ & .06 & .3 \\
\hline MR jet vena contracta, $\mathrm{cm}$ & $0.7 \pm 0.02$ & - & $0.7 \pm 0.01$ & & NA & .9 \\
\hline
\end{tabular}

Values are mean $\pm \mathrm{SD}$ when appropriate. ANOVA, Analysis of variance; $L V$, left ventricular; $L V E D$, left ventricular end diastolic; $L V E F$, left ventricular ejection fraction; $L V E S$, left ventricular end systolic; $M R$, mitral regurgitation; $M V A$, mitral valve annuloplasty; $M V R$, mitral valve replacement; $N A$, not available; SPAP, systolic pulmonary arterial pressure.

After surgery, both mitral peak and mean transvalvular gradients increased, with no significant difference between the 2 groups. Preoperative SPAP was $40 \mathrm{~mm} \mathrm{Hg}$ or more in 26 patients $(37 \%)$, with no significant difference between the 2 groups (MVA group: $\mathrm{n}=14,40 \%$ vs MVR group: $\mathrm{n}=12,34 \%, P=.64)$.

\section{Comparison of Postoperative Resting and Exercise Echocardiographic Data}

Percentage of age-predicted maximal heart rate, maximal workload, peak systolic blood pressure, and heart rate were not significantly different between the MVA and MVR groups (Table 3). At rest, none of the postoperative Doppler echocardiographic variables, including IEOA, were different between the MVA and MVR groups (Table 3). LVEF significantly increased during exercise, with no difference between the 2 groups. The exercise-induced increase in cardiac output and cardiac index was significant in both groups $(P<.01$ for all), but higher in the MVR group (Table 3, $P=.014$ for interaction MVA/MVR, for both parameters). Exercise net compliance significantly decreased, with no differences between the 2 groups.

TABLE 3. Exercise Doppler-echocardiographic data

\begin{tabular}{|c|c|c|c|c|}
\hline & \multicolumn{2}{|c|}{$\operatorname{MVR}(\mathbf{n}=35)$} & \multicolumn{2}{|c|}{$\operatorname{MVA}(\mathbf{n}=\mathbf{3 5})$} \\
\hline & Rest & Exercise & Rest & Exercise \\
\hline \multicolumn{5}{|l|}{ Exercise capacity } \\
\hline Heart rate, beats/min & $71 \pm 8$ & $114 \pm 13^{*}$ & $73 \pm 12$ & $124 \pm 14^{*}$ \\
\hline Percentage of age-predicted heart rate, $\%$ & - & $74 \pm 10$ & - & $79 \pm 9$ \\
\hline Systolic blood pressure, $\mathrm{mm} \mathrm{Hg}$ & $133 \pm 14$ & $174 \pm 14^{*}$ & $136 \pm 12$ & $174 \pm 14 *$ \\
\hline Workload, Watt & - & $94 \pm 17$ & - & $95 \pm 21$ \\
\hline \multicolumn{5}{|l|}{ LV function } \\
\hline LVEF, \% & $41 \pm 6$ & $49 \pm 7 *$ & $39 \pm 4$ & $48 \pm 7 *$ \\
\hline Net atrioventricular compliance, $\mathrm{mL} / \mathrm{mm} \mathrm{Hg}$ & $4.5 \pm 5$ & $2.4 \pm 0.5^{*}$ & $4.1 \pm 3.1$ & $2.2 \pm 0.7 *$ \\
\hline Cardiac output, L/min & $5 \pm 1$ & $9 \pm 1.5^{*}$ & $5 \pm 1$ & $8 \pm 1.5^{*}, \dagger$ \\
\hline Cardiac index, $\mathrm{L} / \mathrm{min} / \mathrm{m}^{2}$ & $3 \pm 0.8$ & $5.6 \pm 1.2^{*}$ & $2.8 \pm 0.6$ & $4.7 \pm 0.9^{*}, \dagger$ \\
\hline \multicolumn{5}{|l|}{ Mitral valve hemodynamics } \\
\hline $\mathrm{EOA}, \mathrm{cm}^{2}$ & $2 \pm 0.4$ & $2.3 \pm 0.4 *$ & $2 \pm 0.6$ & $1.9 \pm 0.4 \dagger$ \\
\hline IEOA, $\mathrm{cm}^{2} / \mathrm{m}^{2}$ & $1.3 \pm 0.3$ & $1.4 \pm 0.2 *$ & $1.2 \pm 0.3$ & $1.2 \pm 0.2 \dagger$ \\
\hline Mitral peak gradient, $\mathrm{mm} \mathrm{Hg}$ & $10 \pm 4$ & $15.6 \pm 8.2^{*}$ & $9 \pm 3$ & $19.5 \pm 7 *$ \\
\hline Mitral mean gradient, $\mathrm{mm} \mathrm{Hg}$ & $5 \pm 2$ & $9.3 \pm 4^{*}$ & $4 \pm 1.3$ & $11.2 \pm 4^{*}$ \\
\hline SPAP, $\mathrm{mm} \mathrm{Hg}$ & $33 \pm 6$ & $42 \pm 6^{*}$ & $37 \pm 9$ & $55 \pm 12^{*}, \dagger$ \\
\hline MR jet vena contracta width, $\mathrm{cm}$ & - & - & $0.1 \pm 0.1$ & $0.2 \pm 0.2$ \\
\hline
\end{tabular}

Values are mean $\pm \mathrm{SD}$ when appropriate. $E O A$, Effective orifice area; $I E O A$, indexed effective orifice area; $L V$, left ventricular; $L V E F$, left ventricular ejection fraction; $M R$, mitral regurgitation; $M V A$, mitral valve annuloplasty; $M V R$, mitral valve replacement; $S P A P$, systolic pulmonary arterial pressure. $* P<.05$ (rest vs exercise). $\dagger P<.05$ (MVA vs MVR). 


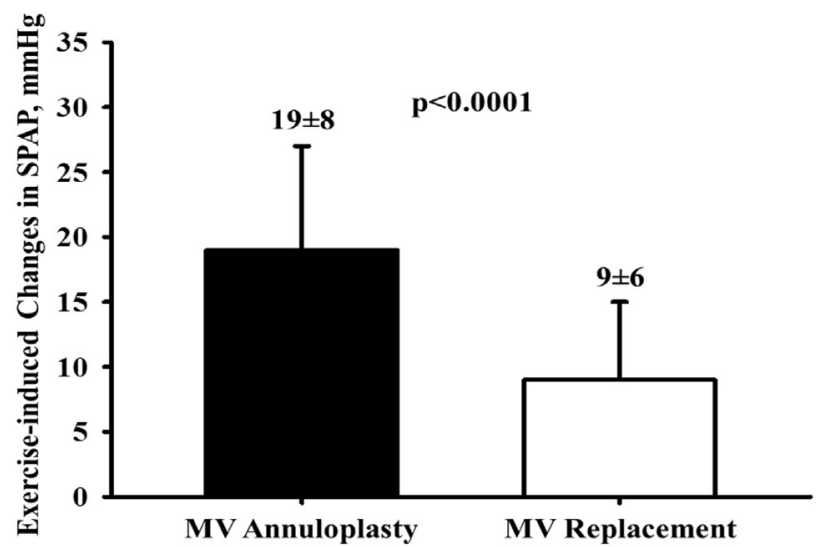

A

$2^{\circ}$

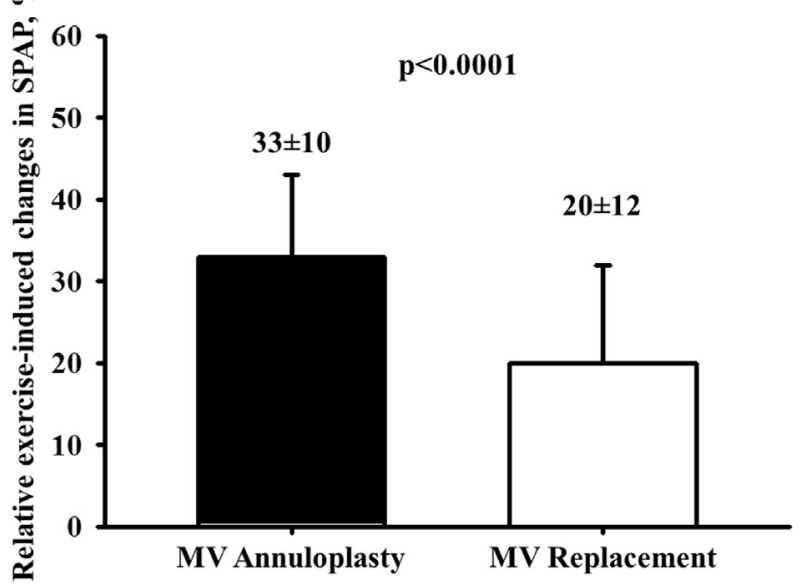

B

FIGURE 1. Absolute (A) and relative (B) exercise-induced changes in SPAP according to surgical technique (MVA vs MVR). $M V$, Mitral valve; SPAP, systolic pulmonary arterial pressure.

Exercise-induced increase in mean and peak transmitral pressure gradients were statistically similar in both groups (Table 3). Exercise SPAP was significantly higher in the MVA group compared with the MVR group $(55 \pm 12 \mathrm{~mm}$ $\mathrm{Hg}$ vs $42 \pm 6 \mathrm{~mm} \mathrm{Hg}, P=.0001$, respectively; Table 3 ). Absolute and relative exercise-induced increases in SPAP were significantly higher in the MVA group (Figure 1).

During exercise, EOA and IEOA increased significantly only in patients receiving MVR (MVR: $+0.23 \pm 0.04$ $\mathrm{cm}^{2}$ vs MVA: $-0.1 \pm 0.09 \mathrm{~cm}^{2}, P=.001$, for EOA; MVR: $+0.14 \pm 0.03 \mathrm{~cm}^{2} / \mathrm{m}^{2}$ vs MVA: $-0.04 \pm 0.07$ $\mathrm{cm}^{2} / \mathrm{m}^{2}, P=.03$, for IEOA, Figure 2). Exercise SPAP was inversely correlated with exercise IEOA $(r=-0.45$; $P=.01$, Figure 3).

At the multivariable analysis, MVA, exercise IEOA, and resting peak transmitral pressure gradient were independent predictors of exercise SPAP (Table 4).

By using receiver operating characteristic curve analysis, the best resting echocardiographic predictors of the
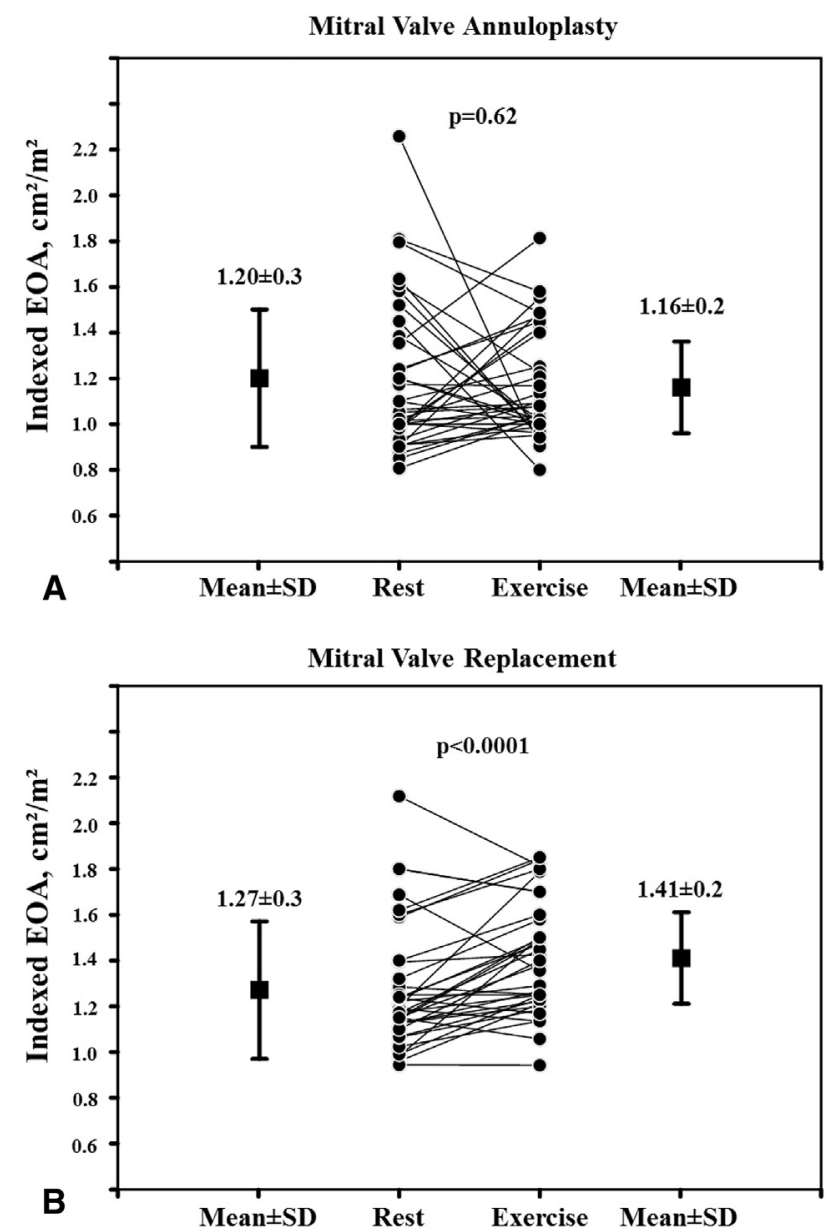

FIGURE 2. Mitral valve opening reserve assessed as the individual exercise-induced changes in IEOA for MVA (A) and MVR (B) groups. $E O A$, Effective orifice area; $S D$, standard deviation.

occurrence of exercise PH were IEOA (AUC $=0.77$ ), mean pressure gradient $(\mathrm{AUC}=0.70)$, and SPAP $($ AUC $=0.74)$. The best cutoff value for resting IEOA was $1.1 \mathrm{~cm}^{2} / \mathrm{m}^{2}($ sensitivity $=79 \%$, specificity $=62 \%)$.

\section{DISCUSSION}

To the best of our knowledge, this study is the first to compare resting and exercise hemodynamic performance of MVA and MVR in patients with FIMR. The main finding of the study is that compared with a matched group of MVR, patients receiving a successful MVA (ie, without persistent or recurrent significant MR) had worse mitral hemodynamic performance during exercise, resulting in higher SPAP. MVA was associated with an absence of mitral opening reserve and in approximately $29 \%$ of exercise PH. In multivariate analysis, reduced IEOA, resting peak gradients, and MVA were independent predictors of postoperative elevated SPAP. 


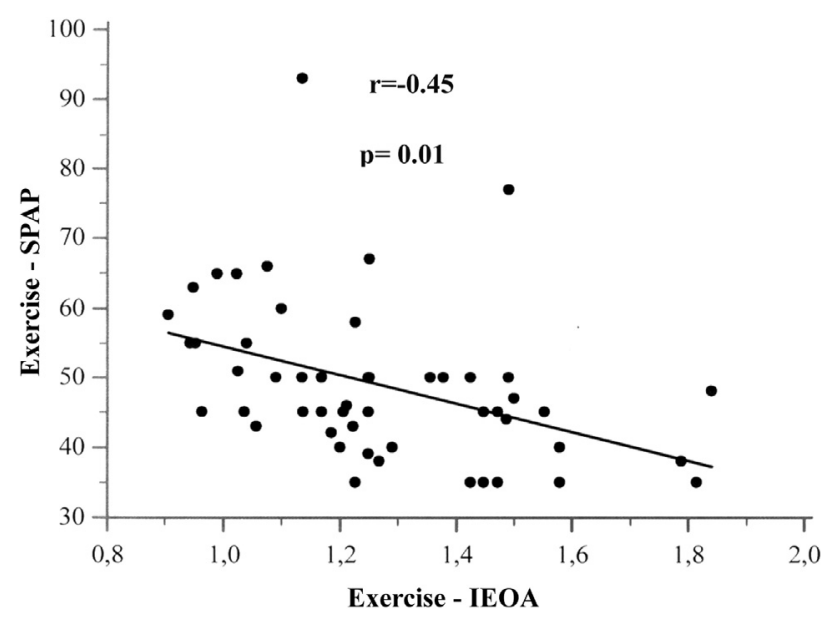

FIGURE 3. Relationship between exercise SPAP and IEOA during exercise. IEOA, Indexed effective orifice area; SPAP, systolic pulmonary arterial pressure.

\section{Pathophysiologic Implications}

The complex pathophysiologic mechanism underlying FIMR is related to the outward displacement of the posterior and anterior papillary muscles as a result of LV remodeling, which causes annular dilatation, leaflet tethering, and mitral valve deformation, eventually leading to a miscoaptation with central or posterior regurgitation jet. The displacement, causing separation of the papillary muscles, puts both the second-order and the free-edge first-order chordae under tension, reducing the flexibility of most part of the anterior leaflet and impairing its mobility. ${ }^{16}$ MVA, by insertion of a ring, fixes the posterior leaflet and further restricts its opening. ${ }^{17}$ The mitral valve motion may become more resistant to transvalvular flow with consequent restriction of its opening. In addition, the anterior displacement of the posterior annulus caused by the prosthetic ring further increases the subvalvular tethering, leading to a reduction of the mitral valve opening in term of functional reserve. ${ }^{18}$ These pathophysiologic consequences explain the decrease in the mitral valve area and the transmitral gradient increment, which worsens significantly after exercise. ${ }^{6}$

Conversely, in patients with MVR, the increase in transvalvular flow rate during exercise may lead to a higher EOA than at rest. These dynamic improvements, combined with the exercise-induced changes in atrioventricular

TABLE 4. Independent determinants of exercise systolic pulmonary arterial pressure

\begin{tabular}{lclc}
\hline & $\boldsymbol{\beta}$ & $\boldsymbol{S E}$ & $\boldsymbol{P}$ value \\
\hline MVA & -0.4 & 2.1 & .0001 \\
Exercise IEOA & -0.34 & 4 & .001 \\
Resting mitral peak gradient & 0.3 & 0.3 & .0001 \\
\hline
\end{tabular}

IEOA, Indexed effective orifice area; $M V A$, mitral valve annuloplasty; $S E$, standard error. compliance, contribute to the transprosthetic gradient reduction limiting, as a consequence, the increase in SPAP.

\section{Comparison With Previous Studies}

In patients undergoing MVA, we previously found a significant reduction of resting and exercise EOA and IEOA, along with increased mitral gradients and SPAP. ${ }^{5}$ Kubota and colleagues ${ }^{6}$ reported a persistent subvalvular leaflet tethering as a frequent cause of postoperative functional mitral stenosis, with a significant exercise-induced hemodynamic worsening symptom.

In the current study, we found that during exercise, despite substantial increase in cardiac output, cardiac index, and transmitral flow rate, the EOA did not increase in patients with MVA, resulting in a significant increase in transvalvular pressure gradients. Patients with MVR also developed higher exercise cardiac output and cardiac index, but the concomitant marked improvement in EOA, likely because of the presence of mitral valve opening reserve, led to less increase in mean and peak transvalvular pressure gradients. These observations are consistent with previous studies $^{19}$ and reinforce the concept that after MVA, the annular reduction does not relieve subvalvular tethering and further impairs mitral valve hemodynamics.

Different from other studies, ${ }^{13,14}$ the current study found no significant relationship from rest to exercise between compliance and SPAP. However, we focused only on patients undergoing operation for FIMR, whereas the previous series mainly included patients with mitral stenosis and preserved LVEF. There was also a significant decrease of compliance during exercise, although no significant differences were observed between MVA and MVR cases.

As shown by Li and colleagues, ${ }^{20}$ IEOA was, in multivariate analysis, the strongest independent parameter associated with exercise SPAP, confirming its role as main factor influencing valve hemodynamics and predicting adverse outcomes. ${ }^{21}$

\section{Clinical Implications}

In line with other findings, ${ }^{6}$ the current study showed that patients with MVA may have a reduced EOA, IEOA, and lack in mitral opening reserve, with a consequent high rate of postoperative exercise $\mathrm{PH}$. Consequently, the negative effect of MVA seems related to the ring itself, being unable to correct the subvalvular tethering and, in some cases, worsening it. In this regard, the best approach would be to perform less restrictive MVA, targeting the reduction of the subvalvular tethering to improve the postoperative hemodynamic performance. However, this potential advantage would likely be offset by a substantial rate of persistent/recurrent $\mathrm{MR}$, which is known to be associated with poor prognosis. ${ }^{22}$ 
The insertion of a prosthesis, which is not influenced by subvalvular tethering, would lead to better hemodynamic performance under exercise. Until the ongoing National Institutes of Health-funded clinical trial is completed, the surgical strategy in patients with FIMR remains controversial and partially guided by the surgeon's expertise and center experience.

\section{Study Limitations}

This study reports retrospective data and thus is subject to all the limitations inherent to this design. We did not measure oxygen extraction at rest and during exercise to exclude patients' physical conditioning as a cause of the differences in pulmonary artery pressures. However, this should not change the main finding of the present study. The choice of MVA or MVR, which was left to the surgeon performing each operation, may represent a bias in the distribution of baseline characteristics between groups. Preoperative data, such as annular size, tenting height, or tenting area, were available only in a small subset of patients, precluding a meaningful conclusion. The postoperative echocardiographic examinations were not performed at a similar interval of time from surgery. However, it is unlikely that this difference had an impact on exercise mitral valve hemodynamic performance. Mechanical and biological prostheses were included in the analysis, but prosthesis opening is not influenced by the subvalvular apparatus. Finally, the results of our study cannot be automatically applied to the newer rings specifically designed to correct FIMR.

\section{CONCLUSIONS}

In patients with FIMR, MVA may result in worse hemodynamic performance than MVR, particularly during exercise. MVA was associated with poor exercise mitral hemodynamic performance, lack of mitral valve opening reserve, and markedly elevated postoperative exercise SPAP compared with MVR. These results confirm that the surgical treatment of FIMR is suboptimal, suggesting that procedures targeting the correction of the underlying pathophysiologic mechanisms should be encouraged. Nonetheless, further studies are needed to confirm our findings and to determine the potential relationship between the postoperative elevated SPAP reported in the MVA group and the outcome of these patients.

The authors thank Professor Luc A. Pierard (University of Liege, Belgium).

\section{References}

1. Grigioni F, Enriquez-Sarano M, Zehr KJ, Bailey KR, Tajik AJ. Ischemic mitral regurgitation: long-term outcome and prognostic implications with quantitative Doppler assessment. Circulation. 2001;103:1759-64.
2. Mitesh VB, Subodh V, Vivek R. Surgical management of ischemic mitral regurgitation. Circulation. 2009;120:1287-93.

3. Lorusso R, Gelsomino S, Vizzardi E, D'Aloia A, De Cicco G, Fabiana Luc F, et al., and the ISTIMIR Investigators. Mitral valve repair or replacement for ischemic mitral regurgitation? The Italian study on the treatment of ischemic mitral regurgitation (ISTIMIR). J Thorac Cardiovasc Surg. 2013;145:128-39.

4. Bolling SF, Pagani FD, Deeb GM, Bach DS. Intermediate term outcome of mitral reconstruction in cardiomyopathy. J Thorac Cardiovasc Surg. 1998; 115:381-6.

5. Magne J, Sénéchal M, Mathieu P, Dumesnil JG, Dagenais F, Pibarot P. Restrictive annuloplasty for ischemic mitral regurgitation may induce functional mitral stenosis. J Am Coll Cardiol. 2008;51:1692-701.

6. Kubota K, Otsuji Y, Ueno T, Koriyama C, Levine RA, Sakata R, et al. Functional mitral stenosis after surgical annuloplasty for ischemic mitral regurgitation: importance of subvalvular tethering in the mechanism and dynamic deterioration during exertion. J Thorac Cardiovasc Surg. 2010;140:617-23.

7. Magne J, Mathieu P, Dusmenil JG, Tannè D, Dagenais F, Doyle D, et al. Impact of prosthesis-patient mismatch on survival after mitral valve replacement. Circulation. 2007;115:1417-25.

8. Gillinov M. Is ischemic mitral regurgitation an indication for surgical repair of replacement? Heart Fail Rev. 2006;11:231-9.

9. Vassileva CM, Boley T, Markwell S, Hazelrigg S. Meta-analysis of short-term and long-term survival following repair versus replacement for ischemic mitral regurgitation. Eur J Cardiothorac Surg. 2011;39:295-303.

10. Picano E, Pibarot P, Lancellotti P, Monin JL, Bonow RO. The emerging role of exercise testing and stress echocardiography in valvular heart disease. $J \mathrm{Am}$ Coll Cardiol. 2009;54:2251-60.

11. Borger MA, Alam A, Murphy P, Doenst T, Tirone ED. Chronic ischemic mitra regurgitation: repair, replace or rethink? Ann Thorac Surg. 2006;81:1153-61.

12. Lang RM, Bierig M, Devereux RB, Flachskampf FA, Foster E, Pellikka PA, et al Recommendations for chamber quantification: a report from the American Society of Echocardiography's Guidelines and Standards Committee and the Chamber Quantification Writing Group, developed in conjunction with the European Association of Echocardiography, a branch of the European Society of Cardiology. Chamber Quantification Writing Group; American Society of Echocardiography's Guidelines and Standards Committee; European Association of Echocardiography. J Am Soc Echocardiogr. 2005;18:1440-63.

13. Li M, Dèry JP, Dusmenil JG, Boudreault JR, Jobin J, Pibarot P. Usefulness of measuring net atrioventricular compliance by Doppler echocardiography in patients with mitral stenosis. Am J Cardiol. 2005;96:432-5.

14. Schwammenthal E, Vered Z, Agranat O, Kaplinsky E, Rabinowitz B Feinberg MS. Impact of atrioventricular compliance on pulmonary arterial pressure in mitral stenosis: an exercise echocardiographic study. Circulation. 2000; 102:2378-84.

15. Pepi M, Tamborini G, Galli C, Barbier P, Doria E, Berti M, et al. A new formula for echo-Doppler estimation of right ventricular systolic pressure. J Am Soc Echocardiogr. 1994; 7:20-6

16. Yellin EL, Peskin C, Yoran C, Koenigsberg M, Matsumoto M, Laniado S, et al Mechanisms of mitral valve motion during diastole. Am J Physiol Heart Circ Physiol. 1981;241:H389-400.

17. Green GR, Dagum P, Glasson JR, Nistal JF, Daughters GT, Ingels NB, et al Restricted posterior leaflet motion after mitral ring annuloplasty. Ann Thorac Surg. 1999;68:2100-6.

18. Zhu F, Otsuji Y, Yotsumoto G, Yuasa T, Ueno T, Yu B, et al. Mechanism of persistent ischemic mitral regurgitation after annuloplasty: importance of augmented posterior mitral leaflet tethering. Circulation. 2005;112:I-396-401.

19. Hobson NA, Wilkinson GAL, Cooper GJ, Wheeldom NM, Lynch J. Hemodynamic assessment of mitral mechanical prostheses under high flow conditions: Comparison between dynamic exercise and dobutamine stress. J Heart Valve Dis. 2006;15:87-91.

20. Li M, Dumesnil JG, Mathieu P, Pibarot P. Impact of valve prosthesis-patient mismatch on pulmonary arterial pressure after mitral valve replacement. J Am Coll Cardiol. 2005;45:1034-40.

21. Pibarot P, Dusmenil JG. Prosthesis-patient mismatch: definition, clinical impact, and prevention. Heart. 2006;92:1022-91.

22. Hung J, Papakostas L, Tahta SA, Hrady BG, Bollen B, Duran C, et al. Mechanism of recurrent ischemic mitral regurgitation after annuloplasty: continued LV remodeling as a moving target. Circulation. 2004;110(Suppl II):II-85-90. 
TABLE E1. Preoperative demographic and clinical data

\begin{tabular}{|c|c|c|c|c|}
\hline & $\frac{\text { All patients }}{(n=114)}$ & $\frac{\text { MVR }}{(n=57)}$ & $\frac{\text { MVA }}{(n=57)}$ & $P$ \\
\hline \multicolumn{5}{|l|}{ Demographic data } \\
\hline Male, n (\%) & $67(58.8)$ & $31(54.4)$ & $36(63.2)$ & .44 \\
\hline Age, y & $65.1 \pm 5.7$ & $66.5 \pm 5.7$ & $63.7 \pm 5.4$ & .007 \\
\hline $\operatorname{BSA}\left(\mathrm{m}^{2}\right)$ & $1.71 \pm 0.18$ & $1.68 \pm 0.19$ & $1.74 \pm 0.17$ & .07 \\
\hline \multicolumn{5}{|l|}{ Clinical data } \\
\hline Diabetes, n (\%) & $25(21.9)$ & $14(24.6)$ & $11(19.3)$ & .65 \\
\hline $\begin{array}{l}\text { Systemic hypertension, } \\
\mathrm{n}(\%)\end{array}$ & $70(61.4)$ & $39(68.4)$ & $31(54.4)$ & .12 \\
\hline Smoking history, $\mathrm{n}(\%)$ & $70(61.4)$ & $33(57.9)$ & $37(64.9)$ & .56 \\
\hline Dyslipidemia, n (\%) & $71(62.3)$ & $40(70.2)$ & $31(54.4)$ & .12 \\
\hline $\begin{array}{l}\text { NYHA class III/IV, } \\
\text { n }(\%)\end{array}$ & $62(54.4)$ & $26(54.4)$ & $26(54.4)$ & 1 \\
\hline \multicolumn{5}{|l|}{ Operative data } \\
\hline CPB time (min) & $106 \pm 35$ & $106 \pm 32$ & $106 \pm 38$ & .96 \\
\hline ACC time (min) & $86 \pm 23$ & $84 \pm 17$ & $87 \pm 27$ & .44 \\
\hline $\begin{array}{l}\text { CABG (No. of grafts) } \\
\text { Prosthesis type }\end{array}$ & & $2.6 \pm 0.8$ & $2.7 \pm 0.70$ & .61 \\
\hline $\begin{array}{l}\text { Prosthesis type } \\
\text { Mechanical, n (\%) }\end{array}$ & $26(48.1)$ & $26(48.1)$ & & \\
\hline Bioprosthesis, n (\%) & $28(51.9)$ & $28(51.9)$ & & \\
\hline
\end{tabular}

Values are mean $\pm \mathrm{SD}$ when appropriate. $A C C$, Aortic crossclamp; $B S A$, body surface area; $C A B G$, coronary artery bypass grafting; $C P B$, cardiopulmonary bypass; $M V A$, mitral valve annuloplasty; $M V R$, mitral valve replacement; $N Y H A$, New York Heart Association.

TABLE E2. Preoperative and postoperative Doppler-echocardiographic data

\begin{tabular}{|c|c|c|c|c|c|c|}
\hline \multirow[b]{2}{*}{ Variables } & \multicolumn{2}{|c|}{$\operatorname{MVR}(\mathbf{n}=57)$} & \multicolumn{2}{|c|}{ MVA $(\mathbf{n}=\mathbf{5 7})$} & \multicolumn{2}{|c|}{ ANOVA $P$ value } \\
\hline & Preoperative & Postoperative & Preoperative & Postoperative & Within & Between \\
\hline \multicolumn{7}{|l|}{ LV geometry } \\
\hline LVED diameter, $\mathrm{mm}$ & $60.1 \pm 4.8$ & $56.4 \pm 3.7$ & $59.4 \pm 9$ & $53.9 \pm 4.5$ & .001 & .08 \\
\hline LVES diameter, mm & $47.4 \pm 6.6$ & $41.7 \pm 5.2$ & $49.5 \pm 11.6$ & $43.5 \pm 4.4$ & .001 & .08 \\
\hline Indexed LVED diameter, $\mathrm{mm} / \mathrm{m}^{2}$ & $36 \pm 3.9$ & $34 \pm 3.2$ & $36.1 \pm 4.9$ & $33.2 \pm 2.1$ & .001 & .62 \\
\hline Indexed LVES diameter, $\mathrm{mm} / \mathrm{m}^{2}$ & $27.1 \pm 4.9$ & $27.4 \pm 3$ & $30.5 \pm 5$ & $27.4 \pm 3$ & .001 & .001 \\
\hline \multicolumn{7}{|l|}{ LV function } \\
\hline LVEF, \% & $39.2 \pm 7.5$ & $42.8 \pm 4.6$ & $36.6 \pm 7.4$ & $39.8 \pm 3.8$ & .001 & .02 \\
\hline Heart rate, beats/min & $70 \pm 12$ & $71 \pm 6$ & $71 \pm 5$ & $72 \pm 8$ & .35 & .26 \\
\hline Cardiac output, L/min & $4.4 \pm 0.6$ & $5 \pm 0.8$ & $4.3 \pm 0.4$ & $4.3 \pm 0.7$ & .001 & .001 \\
\hline Cardiac index, $\mathrm{L} / \mathrm{min} / \mathrm{m}^{2}$ & $2.7 \pm 0.5$ & $3 \pm 0.5$ & $2.5 \pm 0.3$ & $2.5 \pm 0.3$ & .001 & .001 \\
\hline \multicolumn{7}{|l|}{ Mitral valve hemodynamics } \\
\hline Peak gradient, mm Hg & $3.5 \pm 0.7$ & $8 \pm 3.3$ & $3.4 \pm 0.8$ & $8.5 \pm 2.1$ & .001 & .47 \\
\hline Mean gradient, $\mathrm{mm} \mathrm{Hg}$ & $1.6 \pm 0.2$ & $4 \pm 1.3$ & $1.6 \pm 0.3$ & $4.6 \pm 1.3$ & .001 & .04 \\
\hline SPAP, $\mathrm{mm} \mathrm{Hg}$ & $38.2 \pm 9.7$ & $31.8 \pm 5.4$ & $40 \pm 9.2$ & $27.2 \pm 6$ & .001 & .003 \\
\hline MR jet vena contracta, $\mathrm{cm}$ & $0.7 \pm 0.07$ & - & $0.72 \pm 0.08$ & - & NA & .37 \\
\hline
\end{tabular}

Values are mean \pm SD when appropriate. $L V$, Left ventricular; $L V E D$, left ventricular end diastolic; $L V E S$, left ventricular end systolic; $M R$, mitral regurgitation; $N A$, not available; $S P A P$, systolic pulmonary arterial pressure; $M V A$, mitral valve annuloplasty; $M V R$, mitral valve replacement; ANOVA, Analysis of variance; $L V E F$, left ventricular ejection fraction. 
TABLE E3. Exercise Doppler-echocardiographic data

\begin{tabular}{|c|c|c|c|c|}
\hline & \multicolumn{2}{|c|}{$\operatorname{MVR}(\mathbf{n}=\mathbf{5 7})$} & \multicolumn{2}{|c|}{$\operatorname{MVA}(\mathbf{n}=\mathbf{5 7})$} \\
\hline & Rest & Exercise & Rest & Exercise \\
\hline \multicolumn{5}{|l|}{ Exercise capacity } \\
\hline Heart rate, beats/min & $72 \pm 8$ & $109 \pm 15^{*}$ & $74 \pm 10$ & $122 \pm 15^{*}, \dagger$ \\
\hline Percentage of age-predicted heart rate, $\%$ & - & $72 \pm 6$ & & $78 \pm 8$ \\
\hline Systolic blood pressure, $\mathrm{mm} \mathrm{Hg}$ & $132 \pm 11$ & $169 \pm 13^{*}$ & $136 \pm 12$ & $134 \pm 14^{*}$ \\
\hline Workload, Watt & - & $95 \pm 14$ & & $96 \pm 19$ \\
\hline \multicolumn{5}{|l|}{ LV function } \\
\hline LVEF, \% & $42 \pm 6$ & $48 \pm 9 *$ & $40 \pm 4 \dagger$ & $49 \pm 6.1 *$ \\
\hline Net atrioventricular compliance, $\mathrm{mL} / \mathrm{mm} \mathrm{Hg}$ & $4 \pm 4$ & $2.5 \pm 0.5^{*}$ & $3.6 \pm 2.6$ & $2.2 \pm 0.6^{*}, \dagger$ \\
\hline Cardiac output, $\mathrm{L} / \mathrm{min}$ & $5.1 \pm 1$ & $8.8 \pm 1.4^{*}$ & $4.6 \pm 1 \dagger$ & $7.6 \pm 1.3^{*}, \dagger$ \\
\hline Cardiac index, $\mathrm{L} / \mathrm{min} / \mathrm{m}^{2}$ & $3.1 \pm 0.9$ & $5.6 \pm 1.3^{*}$ & $2.8 \pm 0.7$ & $4.7 \pm 1^{*}$ \\
\hline \multicolumn{5}{|l|}{ Mitral valve hemodynamics } \\
\hline $\mathrm{EOA}, \mathrm{cm}^{2}$ & $2 \pm 0.5$ & $2.2 \pm 0.4^{*}$ & $1.8 \pm 0.5 \dagger$ & $1.8 \pm 0.4 \dagger$ \\
\hline IEOA, $\mathrm{cm}^{2} / \mathrm{m}^{2}$ & $1.3 \pm 0.3$ & $1.5 \pm 0.3^{*}$ & $1.1 \pm 0.3 \dagger$ & 1.1. $\pm 0.2 \dagger$ \\
\hline Mitral peak gradient, $\mathrm{mm} \mathrm{Hg}$ & $8.4 \pm 4$ & $15.6 \pm 7.9^{*}$ & $8.6 \pm 2.6$ & $19.7 \pm 6.6^{*}, \dagger$ \\
\hline Mitral mean gradient, $\mathrm{mm} \mathrm{Hg}$ & $4.5 \pm 1.9$ & $9.2 \pm 3.8^{*}$ & $4.5 \pm 1.3$ & $11 \pm 3.7^{*}, \dagger$ \\
\hline SPAP, $\mathrm{mm} \mathrm{Hg}$ & $32 \pm 7$ & $43 \pm 11^{*}$ & $38 \pm 7 \dagger$ & $55 \pm 11^{*}, \dagger$ \\
\hline MR jet vena contracta width, $\mathrm{cm}$ & - & - & $0.2 \pm 0.2$ & $0.3 \pm 0.2$ \\
\hline
\end{tabular}

